Nota editorial: Datos suplementarios del trabajo "Evaluación económica de vacunas neumocócicas conjugadas para Chile". Documento presentado sin revisión editorial.

\title{
Evaluación económica de vacunas neumocócicas para Chile
}

\section{Datos Suplementarios}

\section{Modelo de Cohorte para PHiD-CV}

Se realizó una evaluación económica completa de un programa de vacunación anti-neumocóccica (PHiDCV y PCV-13) sobre la población de Chile. Para ello se utilizó un modelo Markov, determinístico, estático y compartimentalizado por edad, desarrollado en Microsoft Excel (2007) por GSK $^{1,2}$, que permite identificar cambios en los costos y los años de vida ajustados por calidad (AVACs) en función del tiempo. El modelo simula el proceso de desarrollo de la enfermedad invasiva (EI), la neumonía, y la otitis media aguda (OMA) causadas por Streptococcus pneumoniae y Haemophilus influenzae no tipificable (HiNT) en una cohorte de recién nacidos en función del tiempo, expresado en 1.128 ciclos mensuales (94 años). El modelo de cohorte analiza 3 estados de enfermedad (EI, neumonía y OMA). Además, permite incorporar las ramas "meningitis por HiNT" y "bacteremia por HiNT", lo que permite analizar el efecto potencial que puede tener PHiD-CV sobre estos eventos. Mediante el uso de la planilla de Excel es posible estimar tanto el resultado sanitario (medido en muertes, número de casos y años de vida ajustados por calidad) como económico (o costos sanitarios) ocurridos durante el seguimiento de la cohorte estudiada, considerando además los costos de mantenimiento del programa de vacunación.

Para el presente estudio, además de las 3 causas de internación mencionadas se consideraron los casos ambulatorios de OMA por cualquier etiología y las secuelas crónicas asociadas a los casos de meningitis (secuelas auditivas y neurológicas). La Tabla 1 resume los supuestos y consideraciones del Caso Base utilizado en el análisis de costo-efectividad.

La identificación de los parámetros locales de Chile a ser incorporados en el modelo estuvo a cargo del Instituto de Efectividad Clínica y Sanitaria de Argentina (IECS; www.iecs.org.ar). Detalles de la obtención de los datos epidemiológicos y económicos utilizados en este análisis han sido descriptos ${ }^{3}$.

Epidemiología

Para adaptar el modelo a las condiciones particulares de Chile se incorporaron datos epidemiológicos locales de las patologías consideradas en el análisis. La obtención de datos locales en países de América Latina y el Caribe resulta una tarea dificultosa debido a que la información suele ser escasa, incompleta y frecuentemente se halla fragmentada. Es por ello que se siguieron diferentes aproximaciones para obtener los mejores datos disponibles. 
Tabla 1. Resumen de las principales supuestos del Caso Base

\begin{tabular}{|c|c|}
\hline Parámetro & Supuesto del Caso Base \\
\hline Perspectiva & Perspectiva del pagador (Sistema de Salud Pública). \\
\hline País & Chile \\
\hline Población & Cohorte de recién nacidos (252.098). \\
\hline Horizonte Temporal & Toda la vida \\
\hline Comparadores & $\begin{array}{l}\text { 1. Sin vacunación. } \\
\text { 2. Vacunación con PCV-13. } \\
\text { 3. Vacunación con PHiD-CV. }\end{array}$ \\
\hline Efecto indirecto de la vacunación & No se considero el efecto indirecto en el caso base. \\
\hline Prevalencia de HiNT en OMA & Se considero una frecuencia de HiNT en OMA del $34,1 \%^{13}$ \\
\hline Protección cruzada & $\begin{array}{l}\text { Solo para el caso de enfermedades invasivas, se considera protección } \\
\text { cruzada contra los serotipos } 6 \mathrm{~A} \text { y } 19 \mathrm{~A} \text {. }\end{array}$ \\
\hline Cobertura de la vacunación & $\begin{array}{l}\text { 95\% de la población vacunada recibe el esquema completo de vacunación } \\
\text { (igual para PCV-13 y PHiD-CV). }\end{array}$ \\
\hline Esquema de vacunación & $\begin{array}{l}\text { El mismo para ambas vacunas. Dos dosis (a los } 2 \text {, y } 4 \text { meses) más un } \\
\text { refuerzo al mes } 12 \text {. }\end{array}$ \\
\hline Costo de la vacunación & $\begin{array}{l}\text { Se utilizaron los precios del Fondo Rotatorio de OPS del } 2012 \text {. El costo fue } \\
\text { de } 14,12 \text { dólares por dosis para PHiD-CV y } 16,34 \text { dólares por dosis para } \\
\text { PCV }-13^{57} \text {. Se utilizó un } 5 \% \text { de pérdida por desperdicio y } \$ 470 \text { pesos } \\
\text { chilenos por gastos de administración en cada aplicación (equivalente a } 1 \\
\text { dólar) }\end{array}$ \\
\hline Duración de la inmunidad & Hasta los 9 años de edad. \\
\hline $\begin{array}{l}\text { Tasa de descuento (resultados sanitarios } \\
\text { y costos) }\end{array}$ & $\begin{array}{l}\text { Se calculo el valor presente neto de resultados sanitarios y costos } \\
\text { considerando un descuento anual de } 6 \% \text {, según las guías chilenas }{ }^{49} \text {. }\end{array}$ \\
\hline
\end{tabular}

Recientemente, el Instituto de Efectividad Clínica y Sanitaria de Argentina (IECS) realizó un par de revisiones sistemáticas de la literatura a fin de identificar y resumir la información relevante sobre incidencia, etiología y uso de recursos sanitarios para OMA y neumonía en población pediátrica de América Latina y el Caribe ${ }^{4,5}$. La información obtenida de estas revisiones fue considerada la mejor evidencia disponible para estas condiciones y grupo etario, y fue incluida en el modelo siempre que fuera apropiado.

Para obtener información faltante requerida por el modelo se siguió una doble estrategia de revisión exhaustiva de la bibliografía y consenso de expertos mediante la metodología Delphi ${ }^{6,7}$. En primera instancia se consultaron distintas fuentes de información científica como bases de datos bibliográficas (MEDLINE, EMBASE y LILACS), resúmenes de los principales congresos regionales de especialidades relacionadas, estadísticas oficiales del Ministerio de Salud de Chile y estadísticas de otros organismos 
internacionales (Organización Mundial de la Salud (OMS), Organización Panamericana de la Salud (OPS), Albert B. Sabin Vaccine Institute, etc.). Además se realizó una búsqueda en Internet empleando para ello meta-buscadores genéricos, y se visitaron los sitios Web de las principales sociedades médicas de la región. Para la búsqueda en bases de datos electrónicas no se empleó ningún tipo de restricción temporal ni de idioma. La aparente estabilidad en el tiempo de los patógenos bacterianos asociados a las condiciones a considerar sugirió como apropiada una ventana temporal irrestricta. Mediante el contacto con expertos locales fue posible acceder a información no publicada (literatura gris), si ésta se encontraba disponible. En total se revisaron los resúmenes de más de 1.500 trabajos, de los cuales se obtuvo el texto completo de 120 artículos identificados como potencialmente relevantes. En todos los casos se revisaron las referencias bibliográficas de los documentos recuperados.

En una segunda etapa se utilizó la metodología Delphi para estimar aquellos datos requeridos por el modelo que no fueron posibles de obtener mediante la revisión de la literatura. Para ello se organizaron tres grupos de expertos locales, dos con orientación pediátrica (uno para patología ambulatoria y otro para internación) y el tercero para adultos. Se efectuaron dos rondas de preguntas las cuales fueron adaptadas al tipo de información esperable según el perfil de profesionales incluidos en cada grupo. En la primera ronda se solicitó a cada miembro que brindara una estimación de la información solicitada. En la segunda ronda se aportó como información adicional la dispersión de los datos obtenidos de la primera, y cada miembro del grupo tuvo oportunidad de ajustar su estimación. Si existiera información publicada para regiones de Chile u otros países en relación a alguna de las preguntas realizadas a los miembros del panel, ésta fue brindada como orientación en esta instancia.

Para transformar las tasas utilizadas en número absoluto de eventos, el modelo recurre al número de individuos de la cohorte de recién nacidos chilenos del año 2010 (252.098) ${ }^{8}$ en función del tiempo según la mortalidad general para Chile para el $2009^{9}$. Todos los datos de Chile incluidos en el modelo fueron revisados por expertos locales para garantizar que se ajusten a la realidad del país.

En líneas generales, las tasas de internación y mortalidad por neumonía, meningitis, y sépsis, fueron obtenidas del Departamento de Estadísticas e Información de Salud (DEIS) ${ }^{10}$, suponiendo una cobertura del $94 \%$ de la población chilena según lo reportado por el WHOSIS ${ }^{11}$, para su posterior ajuste a toda la población.

\section{Neumonía}

El modelo requiere la tasa de internaciones y casos ambulatorios por neumonías de cualquier etiología (ver Tabla 2). Además se debe incorporar la letalidad del caso internado (probabilidad de muerte), para lo que se asumió que todos los decesos ocurren durante la internación ${ }^{10}$. La tasa anual de casos ambulatorios por grupo etario fue calculada a partir de la tasa de internación, teniendo en cuenta el porcentaje de los casos de neumonía que se internan, obtenida de la encuesta Delphi. Para el cálculo se utilizó la siguiente ecuación 1: 
Inc.de Neumonías Ambulatorias=

$=$ (Inc. de Neumonías Internadas)/(\% de Neumonías Internadas)- Inc.de Neumonías Internadas

Ecuación 1

Tabla 2. Epidemiología de la neumonía por cualquier causa por rango de edades.

\begin{tabular}{|c|c|c|c|}
\hline $\begin{array}{l}\text { Grupo de } \\
\text { Edad }\end{array}$ & $\begin{array}{c}\text { Tasa anual de } \\
\text { hospitalizaciones } \\
\text { (por } 100.000 \text { habitantes) }\end{array}$ & $\begin{array}{l}\text { Letalidad de la } \\
\text { neumonía }^{1}\end{array}$ & $\begin{array}{c}\text { Tasa anual de consultas } \\
\text { ambulatorias } \\
\text { (por } 100.000 \text { habitantes) }^{2}\end{array}$ \\
\hline$<1$ año & 6526,2 & $0,5 \%$ & 15227,8 \\
\hline 1 año & 1563,2 & $0,1 \%$ & 6252,6 \\
\hline 2 años & 1563,2 & $0,1 \%$ & 6252,6 \\
\hline 3 años & 1563,2 & $0,1 \%$ & 8857,9 \\
\hline 4 años & 1563,2 & $0,1 \%$ & 8857,9 \\
\hline 5-9 años & 388,6 & $0,0 \%$ & 7384,3 \\
\hline 10-14 años & 145,9 & $0,0 \%$ & 2772,9 \\
\hline 15-19 años & 62,0 & $0,7 \%$ & 1178,4 \\
\hline 20-24 años & 51,7 & $0,9 \%$ & 206,6 \\
\hline $25-29$ años & 51,7 & $0,9 \%$ & 206,6 \\
\hline 30-34 años & 77,6 & $1,5 \%$ & 310,4 \\
\hline 35-39 años & 77,6 & $1,5 \%$ & 310,4 \\
\hline 40-44 años & 98,3 & $2,1 \%$ & 393,3 \\
\hline 45-49 años & 98,3 & $2,1 \%$ & 163,9 \\
\hline 50-54 años & 237,5 & $2,1 \%$ & 395,9 \\
\hline 55-59 años & 237,5 & $2,1 \%$ & 395,9 \\
\hline 60-64 años & 599,8 & $3,1 \%$ & 999,7 \\
\hline 65-69 años & 599,8 & $3,1 \%$ & 257,1 \\
\hline 70-74 años & 1878,2 & $5,1 \%$ & 805,0 \\
\hline $75-79$ años & 1878,2 & $5,1 \%$ & 805,0 \\
\hline 80-84 años & 5364,5 & $16,6 \%$ & 2299,1 \\
\hline 85-89 años & 5364,5 & $16,6 \%$ & 2299,1 \\
\hline 90 años o mas & 5364,5 & $16,6 \%$ & 2299,1 \\
\hline
\end{tabular}

\footnotetext{
${ }_{1}^{1}$ Basado en egresos hospitalarios del Departamento de Estadísticas e Información de Salud (DEIS) ${ }^{10}$

${ }^{2}$ Para la estimación del número de casos ambulatorios se utilizaron la tasa anual de hospitalización por cada 100.000 habitantes y el porcentaje de casos de neumonía que requieren internación (basado en panel Delphi).
} 
Otitis Media Aguda (OMA)

El modelo incorpora la tasa anual de casos (ambulatorios) ${ }^{12}$ y número total de miringotomías atribuibles a OMA de cualquier etiología en Chile (ver Tabla 3). Además el modelo puede considerar el porcentaje de los casos que evolucionan con discapacidad auditiva, (no fue incluido en el caso base analizado). La frecuencia de miringotomias y de secuelas auditivas (no incluidas en el caso base) fue estimada a partir de paneles Delphi.

En cuanto a la etiología de la OMA en Chile, se utilizo el estudio de Rosenblüt y col $2012^{13}$ que describe que un $35,4 \%$ de los casos de OMA son debidos a Streptococcus pneumoniae, mientras que un $34,1 \%$ adicional es producido por Haemophilus influenzae no tipificable. Dentro de los casos atribuibles a Streptococcus pneumoniae, los serotipos cubiertos por la vacuna PCV-13 dan cuenta de un 89,5\%, mientras que los cubiertos por PHiD-CV son responsables del 76,2\% ${ }^{4}$. Estos datos fueron utilizados para calcular la efectividad vacunal contra OMA en Chile.

\section{Enfermedad invasiva neumocóccica}

Tanto la meningitis como la bacteremia son formas de enfermedad invasiva causadas por neumococo. Para analizar el impacto de la vacunación sobre ambas condiciones el modelo requiere la tasa de incidencia y la letalidad respectivas, considerándose únicamente los casos que requieren internación. La Tabla 4 muestra los datos utilizados para meningitis neumocóccica, mientras que la Tabla 5 detalla la información para bacteremia por igual etiología. La tasa de incidencia de meningitis neumocóccica se calculó a partir de los datos de incidencia de meningitis por cualquier causa y el porcentaje de casos de meningitis que son debidos a Streptococcus pneumoniae. Para ello se utilizó la siguiente ecuación 2:

Incidencia Meningitis $\mathrm{sp}_{\mathrm{s}}$ Incidencia Meningitis $\times \% \mathrm{M}_{\mathrm{sp}}$

Ecuación 2

donde, Incidencia Meningitis $s_{\mathrm{sp}}$ incidencia de meningitis neumocóccica; Incidencia Meningitis: incidencia de meningitis por cualquier causa; \% $\mathrm{M}_{\mathrm{sp}}$ : proporción de las meningitis atribuidas a neumococo. La misma metodología se utilizó para estimar la incidencia de bacteremia neumocóccica. De esta forma es posible incorporar en la ecuación aquellos casos de enfermedad invasiva sin diagnóstico etiológico. Para los casos de meningitis se consideró como información adicional la probabilidad de presentar secuelas neurológicas y/o auditivas a largo plazo. En comparación, se asumió que los casos de bacteremia evolucionan sin secuelas permanentes. 
Tabla 3. Epidemiología de la otitis media aguda por cualquier causa por rango de edades.

\begin{tabular}{|c|c|c|c|}
\hline Grupo de Edad & $\begin{array}{l}\text { Casos Ambulatorios Anuales } \\
\text { (por } 100,000 \text { habitantes) }^{1}\end{array}$ & $\begin{array}{c}\text { Miringotomías anuales } \\
\text { (por } 100.000 \text { habitantes) }^{2}\end{array}$ & $\begin{array}{c}\text { Casos anuales con } \\
\text { secuelas } \\
\text { (por } 100,000^{\text {habitantes) }}\end{array}$ \\
\hline$<1$ año & 16260,2 & 1215,4 & $1.626,0$ \\
\hline 1 año & 13839,3 & 1032,4 & 692,0 \\
\hline 2 años & 10884,4 & 811,3 & 544,2 \\
\hline 3 años & 10256,4 & 764,9 & 410,3 \\
\hline 4 años & 8974,4 & 670,7 & 359,0 \\
\hline 5-9 años & 2882,6 & 734,3 & 72,1 \\
\hline 10-14 años & 2882,6 & 802,9 & 72,1 \\
\hline $15-19$ años & 735,4 & 217,4 & 18,4 \\
\hline 20-24 años & 490,3 & 206,8 & 29,4 \\
\hline $25-29$ años & 399,5 & 151,1 & 24,0 \\
\hline 30-34 años & 399,5 & 143,5 & 24,0 \\
\hline 35-39 años & 399,5 & 148,3 & 24,0 \\
\hline 40-44 años & 399,5 & 149,1 & 24,0 \\
\hline $45-49$ años & 299,6 & 106,6 & 25,5 \\
\hline $50-54$ años & 299,6 & 88,7 & 25,5 \\
\hline 55-59 años & 299,6 & 70,2 & 25,5 \\
\hline $60-64$ años & 307,6 & 58,5 & 26,1 \\
\hline $65-69$ años & 102,3 & 28,0 & 12,8 \\
\hline $70-74$ años & 102,3 & 21,0 & 12,8 \\
\hline $75-79$ años & 102,3 & 15,7 & 12,8 \\
\hline $80-84$ años & 102,3 & 7,4 & 12,8 \\
\hline 85-89 años & 102,3 & 5,0 & 12,8 \\
\hline 90 años o mas & 102,3 & 4,1 & 12,8 \\
\hline
\end{tabular}

${ }^{1}$ Basado en la incidencia reportada por Lopez y col $1998^{12}$ hasta los 4 años de edad. Luego se asumió una tasa de declinación de la incidencia similar a la reportada por Cintra y col., XXX para una población cautiva del Centro de Salud de la Facultad de Medicina de Ribeirão Preto en Brasil ${ }^{14}$

${ }^{2}$ Calculado en base a la incidencia de casos ambulatorios y el porcentaje de casos que requerirá miringotomía (obtenido de panel Delphi).

${ }^{3}$ Calculado en base a la incidencia de casos ambulatorios y el porcentaje de casos con secuelas (obtenido de panel Delphi). No considerado en caso base. 
Tabla 4. Epidemiología de la meningitis por neumococo por rango de edades.

\begin{tabular}{|c|c|c|c|c|}
\hline Grupo de Edad & $\begin{array}{l}\text { Incidencia Anual } \\
\text { (por } 100,000 \\
\text { habitantes) }^{1}\end{array}$ & $\begin{array}{c}\text { Letalidad de la } \\
\text { meningitis }\end{array}$ & $\begin{array}{l}\text { Porcentaje de casos } \\
\text { con secuelas } \\
\text { neurológicas }\end{array}$ & $\begin{array}{c}\text { Porcentaje de } \\
\text { casos con } \\
\text { hipoacusia }\end{array}$ \\
\hline$<1$ año & 39,4 & $12,3 \%$ & $25,0 \%$ & $25,0 \%$ \\
\hline 1 año & 5,3 & $10,0 \%$ & $21,0 \%$ & $14,0 \%$ \\
\hline 2 años & 6,1 & $10,0 \%$ & $21,0 \%$ & $14,0 \%$ \\
\hline 3 años & 4,9 & $10,0 \%$ & $19,3 \%$ & $8,3 \%$ \\
\hline 4 años & 5,4 & $10,0 \%$ & $19,3 \%$ & $8,3 \%$ \\
\hline 5-9 años & 3,1 & $10,0 \%$ & $15,0 \%$ & $5,0 \%$ \\
\hline 10-14 años & 1,3 & $10,0 \%$ & $15,0 \%$ & $5,0 \%$ \\
\hline 15-19 años & 0,9 & $10,0 \%$ & $15,0 \%$ & $5,0 \%$ \\
\hline 20-24 años & 1,2 & $2,0 \%$ & $7,3 \%$ & $2,8 \%$ \\
\hline 25-29 años & 1,2 & $2,0 \%$ & $7,3 \%$ & $2,8 \%$ \\
\hline 30-34 años & 1,1 & $2,0 \%$ & $7,3 \%$ & $2,8 \%$ \\
\hline 35-39 años & 1,1 & $2,0 \%$ & $7,3 \%$ & $2,8 \%$ \\
\hline 40-44 años & 1,4 & $2,0 \%$ & $7,3 \%$ & $2,8 \%$ \\
\hline 45-49 años & 1,7 & $5,0 \%$ & $10,1 \%$ & $4,9 \%$ \\
\hline 50-54 años & 2,7 & $5,0 \%$ & $10,1 \%$ & $4,9 \%$ \\
\hline 55-59 años & 2,7 & $5,0 \%$ & $10,1 \%$ & $4,9 \%$ \\
\hline 60-64 años & 3,6 & $5,0 \%$ & $10,1 \%$ & $4,9 \%$ \\
\hline 65-69 años & 2,9 & $17,5 \%$ & $16,9 \%$ & $9,1 \%$ \\
\hline 70-74 años & 4,6 & $17,5 \%$ & $16,9 \%$ & $9,1 \%$ \\
\hline 75-79 años & 4,6 & $17,5 \%$ & $16,9 \%$ & $9,1 \%$ \\
\hline 80-84 años & 4,0 & $17,5 \%$ & $16,9 \%$ & $9,1 \%$ \\
\hline 85-89 años & 4,0 & $17,5 \%$ & $16,9 \%$ & $9,1 \%$ \\
\hline 90 años o mas & 4,0 & $17,5 \%$ & $16,9 \%$ & $9,1 \%$ \\
\hline
\end{tabular}

${ }^{1}$ Basado en egresos hospitalarios del DEIS ${ }^{8}$. El porcentaje de casos atribuibles a neumococo se basan en panel Delphi.

${ }^{2}$ Basado en panel Delphi..

En la Tabla 6 se detalla para cada edad la distribución relativa de los serotipos de neumococo aislados en casos de enfermedad invasiva entre 2000 y 2010. Los datos fueron obtenidos del sistema de vigilancia SIREVA $\|^{15-20}$. Finalmente, la Tabla 7 presenta el porcentaje de casos de enfermedad invasiva asociada a Streptococcus pneumoniae, cubiertas por los serotipos contenidos en PHiD-CV y PCV-13.

Enfermedad invasiva por Haemophilus influenzae no tipificable (HiNT)

Además, para evaluar el impacto potencial de PHiD-CV sobre enfermedad invasiva asociada a HiNT en ciertos escenarios (no incluido en el caso base analizado), la prevalencia de HiNT en enfermedad 
invasiva fue obtenida de una publicación regional del SIREVA ${ }^{21}{ }^{21}$. Gabastou y col., $2008^{21}$, describen una tendencia ascendente en la frecuencia anual de HiNT en la región.

Tabla 5. Epidemiología de la bacteremia por neumococo por rango de edades.

\begin{tabular}{|c|c|c|}
\hline Grupo de Edad & $\begin{array}{c}\text { Incidencia Anual } \\
\text { (por } 100,000 \text { habitantes) }\end{array}$ & $\begin{array}{l}\text { Letalidad de la } \\
\text { bacteremia }\end{array}$ \\
\hline$<1$ año & 61,5 & $7,5 \%$ \\
\hline 1 año & 7,6 & $2,0 \%$ \\
\hline 2 años & 7,6 & $2,0 \%$ \\
\hline 3 años & 0,2 & $2,0 \%$ \\
\hline 4 años & 0,2 & $2,0 \%$ \\
\hline 5-9 años & 0,0 & $2,0 \%$ \\
\hline 10-14 años & 0,0 & $2,0 \%$ \\
\hline 15-19 años & 0,0 & $2,0 \%$ \\
\hline 20-24 años & 0,5 & $12,5 \%$ \\
\hline 25-29 años & 0,5 & $12,5 \%$ \\
\hline 30-34 años & 0,7 & $12,5 \%$ \\
\hline 35-39 años & 0,7 & $12,5 \%$ \\
\hline 40-44 años & 1,2 & $12,5 \%$ \\
\hline $45-49$ años & 1,3 & $22,5 \%$ \\
\hline 50-54 años & 3,3 & $22,5 \%$ \\
\hline $55-59$ años & 3,3 & $22,5 \%$ \\
\hline $60-64$ años & 8,8 & $22,5 \%$ \\
\hline 65-69 años & 11,2 & $30,0 \%$ \\
\hline 70-74 años & 30,0 & $30,0 \%$ \\
\hline 75-79 años & 30,0 & $30,0 \%$ \\
\hline 80-84 años & 69,2 & $30,0 \%$ \\
\hline 85-89 años & 69,2 & $30,0 \%$ \\
\hline 90 años o mas & 69,2 & $30,0 \%$ \\
\hline
\end{tabular}

${ }_{2}^{1}$ Basado en egresos hospitalarios del DEIS ${ }^{8}$. El porcentaje de casos atribuibles a neumococo se basan en panel Delphi.

${ }^{2}$ Basado en panel Delphi.

El $24.7 \%$ de los Haemophilus influenzae analizados entre $2000-2005$ fueron HiNT. El $10 \%$ de los Haemophilus influenzae analizados de enfermedad invasiva en el 2000 y el $36 \%$ de los Haemophilus influenzae analizados de enfermedad invasiva en el 2005 fueron HiNT. Por ello, se estimó para el año 2007 que un 38\% de los Haemophilus influenzae aislados en enfermedad invasiva fueron HiNT. El trabajo reporta 6.753 meningitis y 3.783 sepsis/bacteriemia por Streptococcus pneumoniae y en base a la asunción anteriormente mencionada, se estimo la existencia de 598 casos de meningitis por HiNT (8,8\% de los casos de $S$. pneumoniae) y 229 casos de sepsis/bacteriemia por HiNT (6,1\% de los casos de $S$. pneumoniae). En escenarios adicionales, se incluyó esta frecuencia de enfermedad invasiva por HiNT equivalente al $8,8 \%$ de las meningitis por $S$. pneumoniae y $6,1 \%$ de las sepsis/bacteriemia por $S$. pneumoniae. 
Tabla 6. Distribución de serotipos de Streptococcus pneumoniae. ${ }^{1}$

\begin{tabular}{|c|c|c|c|c|}
\hline \multirow[b]{2}{*}{$\begin{array}{l}\text { Grupo de } \\
\text { Edad }\end{array}$} & \multicolumn{4}{|c|}{ Enfermedad Invasiva } \\
\hline & 0 a 2 años & 2 a 5 años & 5 a 10 años & $>10$ años \\
\hline 1 & $5,6 \%$ & $9,0 \%$ & $40,1 \%$ & $40,1 \%$ \\
\hline 3 & $1,1 \%$ & $0,8 \%$ & $0,5 \%$ & $0,5 \%$ \\
\hline 4 & $2,2 \%$ & $2,0 \%$ & $1,4 \%$ & $1,4 \%$ \\
\hline 5 & $3,8 \%$ & $5,2 \%$ & $7,4 \%$ & $7,4 \%$ \\
\hline $6 \mathrm{~A}$ & $5,8 \%$ & $4,5 \%$ & $2,3 \%$ & $2,3 \%$ \\
\hline $6 \mathrm{~B}$ & $8,0 \%$ & $5,9 \%$ & $1,4 \%$ & $1,4 \%$ \\
\hline $7 \mathrm{~F}$ & $3,8 \%$ & $4,4 \%$ & $6,3 \%$ & $6,3 \%$ \\
\hline $9 \mathrm{~V}$ & $1,1 \%$ & $1,5 \%$ & $1,3 \%$ & $1,3 \%$ \\
\hline 14 & $29,8 \%$ & $27,5 \%$ & $6,6 \%$ & $6,6 \%$ \\
\hline $18 \mathrm{C}$ & $6,3 \%$ & $6,7 \%$ & $4,7 \%$ & $4,7 \%$ \\
\hline $19 \mathrm{~A}$ & $4,8 \%$ & $4,3 \%$ & $2,9 \%$ & $2,9 \%$ \\
\hline $19 \mathrm{~F}$ & $6,5 \%$ & $5,5 \%$ & $2,1 \%$ & $2,1 \%$ \\
\hline $23 \mathrm{~F}$ & $3,6 \%$ & $3,1 \%$ & $4,0 \%$ & $4,0 \%$ \\
\hline Otros & $17,5 \%$ & $19,4 \%$ & $18,9 \%$ & $18,9 \%$ \\
\hline
\end{tabular}

${ }^{1}$ Basado en SIREVA II entre 2000 y $2010 .{ }^{15-20}$

Tabla 7. Porcentaje de los casos de enfermedad invasiva producidos por serotipos cubiertos por la vacunación.

\begin{tabular}{lccc}
\hline Grupo de Edad & PHiD-CV $^{\mathbf{1}}$ & PCV-13 & Fuente \\
\hline $0-2$ años & $76 \%$ & $80 \%$ & \\
$2-5$ años & $75 \%$ & $78 \%$ & SIREVA II ${ }^{15-20}$. \\
$5-10$ años & $78 \%$ & $82 \%$ & \\
$>10$ años & $78 \%$ & $82 \%$ & \\
\hline
\end{tabular}

${ }^{1}$ Considerando la protección cruzada descripta.

Efecto Directo de Vacunas

Los efectos sanitarios directos son aquellos beneficios obtenidos en los individuos vacunados mientras dura la inmunidad (reducción en el número de caso, muertes, procedimientos médicos, internaciones, etc.). El efecto protector de la vacunación fue modelado dependiendo de dos factores: las dosis de vacuna administradas y el tiempo transcurrido desde la vacunación. Tanto para PCV-13 como para PHiDCV se analizó un esquema consistente en dos dosis a los 2 y 4 meses, con un refuerzo en el mes 12 . Una 
vez administrada la primera dosis, la eficacia vacunal o protección directa pasa por tres etapas. Estas etapas fueron descritas y discutidas en detalle para esquemas $3+1$ y $2+1$ previamente ${ }^{22}$. En la primera se asume un incremento gradual de la eficacia hasta que el refuerzo es administrado (punto de eficacia máxima). En la segunda etapa (hasta los 3 años) el nivel de protección es considerado estable, luego de lo cual la eficacia vacunal disminuye progresivamente hasta los diez años de edad. Transcurrido dicho período, el beneficio sobre la población vacunada es el mismo que para la no vacunada. Estos cambios relativos en la eficacia vacunal fueron modelados teniendo en cuenta la opinión de expertos y los cambios en la eficacia de PVC-7 observada por Whitney y colaboradores ${ }^{23}$. La forma de la curva de protección directa es igual para todas las enfermedades estudiadas, sin embargo el valor máximo de protección alcanzado por la vacunación varía para cada condición, según la evidencia científica existente (ver Tabla 8). Toda la información de eficacia vacunal utilizada en los modelos, se basó en las recomendaciones recibidas a partir de consenso de expertos en modelos y en vacunas de neumococo, desarrollado en Setiembre del 2013. Del mismo participaron, Philippe De Wals (Canadá), Ping-Ying Lee (Taiwan), Arto Palmu (Finlandia), Stephen Pelton (EEUU), Mario Ramirez (Portugal), Xavier Saez-Llorenz (Panama).

Eficacia de PHiD-CV y PCV-13 contra neumonía.

La eficacia vacunal de PHiD-CV y PCV-13 contra neumonía se basó en la eficacia vacunal reportada por diversos estudios. Estudios con PCV-7 ${ }^{24,25}$, con una vacuna conjugada experimental de 9 serotipos ${ }^{26-28}$, con una vacuna conjugada experimental de 11 serotipos $^{29}$ y con PHiD-CV (COMPAS) ${ }^{30-32}$ señalan que no hay una tendencia a mayor eficacia en las vacunas con mayor cobertura de serotipos. El estudio COMPAS de PHiD-CV reportó una eficacia vacunal contra neumonía confirmada radiológicamente y neumonía clínica en su cohorte de intención de tratar del $23,4 \%$ y $7,3 \%$, respectivamente. Dado que la vacuna PCV-13 no presenta datos de eficacia contra neumonía y la evidencia previa anteriormente mencionada, se uso valores similares de eficacia vacunal contra neumonía para todas las vacunas. La eficacia contra neumonía confirmada radiológicamente $(23,4 \%)$ fue usada como aproximación a la eficacia contra neumonía hospitalizada y la eficacia contra neumonía clínica $(7,3 \%)$ fue usada como aproximación a la eficacia contra neumonía ambulatoria, para ambas vacunas. Estos valores son muy cercanos a las estimaciones de eficacia que surgen de una revisión reciente de la Colaboración Cochrane ( $27 \%$ de eficacia vacunal contra neumonía confirmada radiológicamente y $6 \%$ de eficacia vacunal contra neumonía clínica) ${ }^{33}$ (Tabla 8).

Eficacia de PHiD-CV y PCV-13 contra otitis media aguda (OMA).

Se consideró que la eficacia de las vacunas PCV-13, PHiD-CV (e incluso PCV-7) contra OMA asociada a serotipos de neumococo cubiertos por la vacuna fue similar en todas ellas. Se utilizo la eficacia vacunal reportada para PHiD-CV en el estudio COMPAS (69,8\%; intervalo de confianza al 95\% (IC95\%): 57\% $70 \%)^{34}$. La eficacia vacunal contra la OMA asociada a los serotipos no cubiertos por la vacuna también fue considerada similar (siguiendo las recomendaciones de expertos) para PCV-13 y PHiD-CV. Se utilizó 
para ambas vacunas la eficacia vacunal descripta por Eskola y col. ${ }^{35}$ para PCV-7 (-33\%), a pesar de que los ensayos clínicos con la vacuna PHiD-CV no se observó el fenómeno de reemplazo ${ }^{34}$. Para estimar la eficacia vacunal contra OMA asociada a Haemophilus influenzae se utilizó datos de Eskola y col. ${ }^{35}$ para PCV-13 y de Sáez-Llorens y col para PHiD-CV ${ }^{34}$. La eficacia vacunal utilizada para PCV-13 contra OMA asociada a Haemophilus influenzae fue -11\% (IC95\%: $-34 \%-8 \%$; reflejando un fenómeno de reemplazo) y la eficacia vacunal utilizada para PHiD-CV contra OMA asociada a Haemophilus influenzae no tipificable fue 20,5\% (IC95\%: $-43 \%-57 \%$ ), en línea con el estudio POET (Prymula y colaboradores ${ }^{36}$ ) previo al COMPAS ${ }^{34}$ (Tabla 8$)$.

Para estimar la efectividad final para prevenir OMA en la población de Chile se multiplicaron cada uno de los valores de eficacia por la prevalencia de los tres grupos de agentes etiológicos considerados, neumococos cubiertos por la vacunación, neumococos no cubiertos y Haemophilus influenzae no tipificable, previamente descriptos. Para ello se empleó la siguiente ecuación 3:

Efectividad $=\% S p c \times$ ESpc $+\%$ Spnc $\times$ ESpnc $+\% H i N T \times$ EHiNT

Ecuación 3

donde, Efectividad: efectividad máxima final alcanzada por la vacunación; \%SpC: porcentaje de los casos de OMA debidos a los serotipos de neumococo cubiertos por la vacuna; ESpC: eficacia contra los serotipos de neumococo cubiertos por la vacuna; \%SpNC: porcentaje de los casos de OMA debidos a los serotipos de neumococo no cubiertos por la vacuna; ESpNC: eficacia contra los serotipos de neumococo no cubiertos por la vacuna (en este caso se utiliza un valor negativo que indica un aumento del riesgo de infección por dichos serotipos); \%HiNT: porcentaje de los casos de OMA debidos a Haemophilus influenzae no tipificable; EHiNT: eficacia contra los serotipos de Haemophilus influenzae no tipificable (en este caso se utiliza un valor negativo para PCV-13 y uno positivo para PHiD-CV).

De esta forma, la efectividad luego del refuerzo (punto de eficacia máxima) para prevenir la OMA fue estimada en $17 \%$ para PCV-13, y en $23 \%$ para PHiD-CV. Para estimar la reducción potencial sobre los procedimientos de miringotomía se realizó una revisión de la literatura y se observó una relación exponencial entre la eficacia vacunal y la incidencia de miringotomías ${ }^{36-42}$ (ver Figura 1). La reducción en la frecuencia de miringotomías fue proporcional a la diferencia relativa observada entre las eficacias contra OMA de las vacunas evaluadas y PCV7. Se observó en los estudios con mayor incidencia de miringotomías, una menor eficacia para estas vacunas. Se puedo ajustar una relación exponencial para cada vacuna según las siguientes formulas (Figura 2 ):

Eficacia de PCV-7 contra miringotomía: 0,2747 $\mathrm{e}^{-15,17 \text { x incidencia de miringotomías }}$

Eficacia de PCV-13 contra miringotomía: 0,3159e $\mathrm{e}^{-15,17 \times \text { incidencia de miringotomías }}$

Eficacia de PHiD-CV contra miringotomía: $0,5165 \mathrm{e}^{-15,17 \times \text { incidencia de miringotomías }}$ 
Esta relación fue validada para el estudio FinIP que también tiene objetivos para evaluación de eficacia contra $\mathrm{OMA}^{42}$ y en base a la incidencia de miringotomias se pudo estimar la eficacia (14\%) con valores cercanos a los observados en el estudio (Figura 2).

Figura 1, Revisión de la eficacia/efectividad de las vacunas conjugadas de neumococo contra miringotomía.

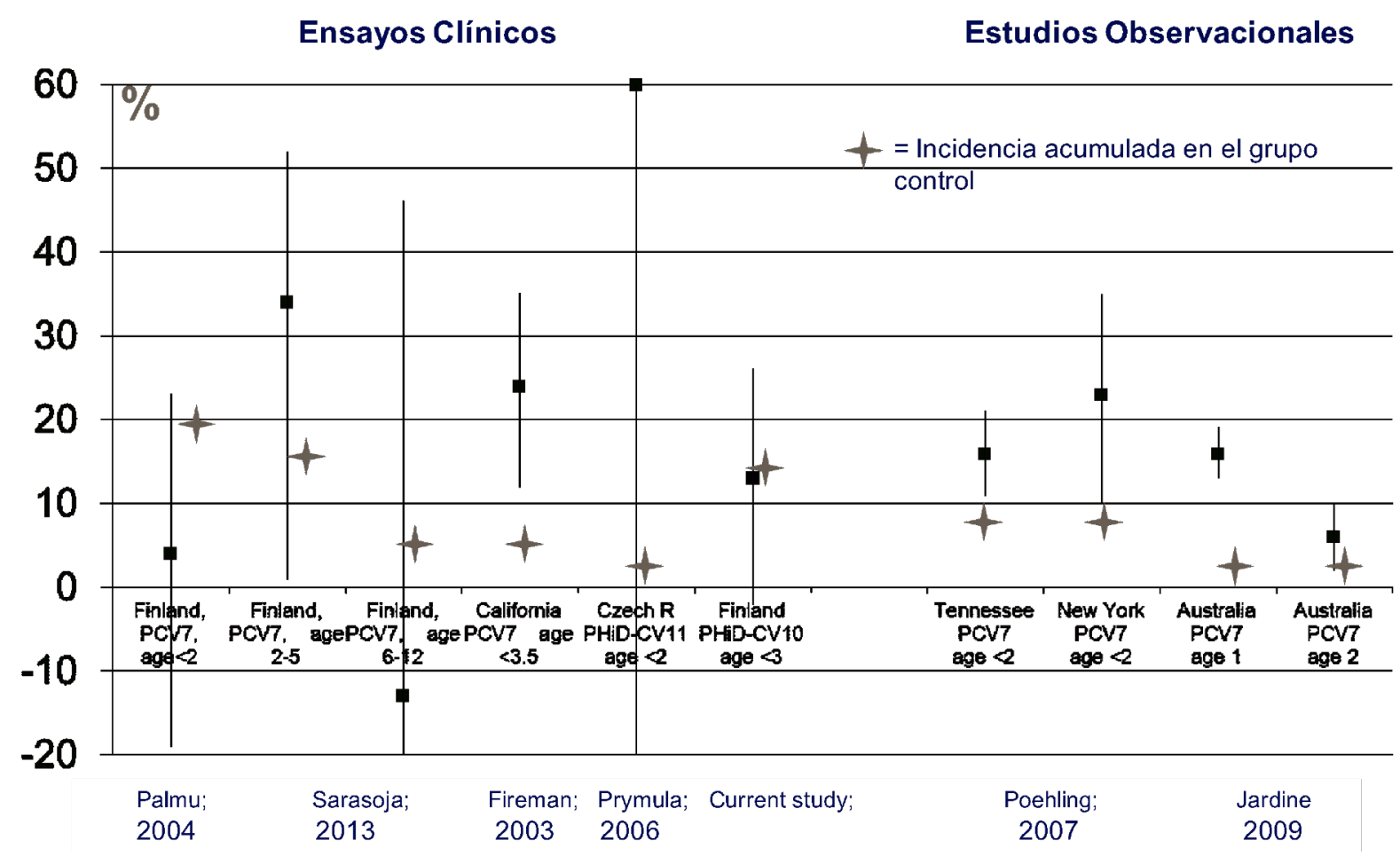

Figura 2, Estimación de la eficacia vacuna en función de la incidencia de miringotomías

Tympanostomy Tube Placement vaccine efficacy functions

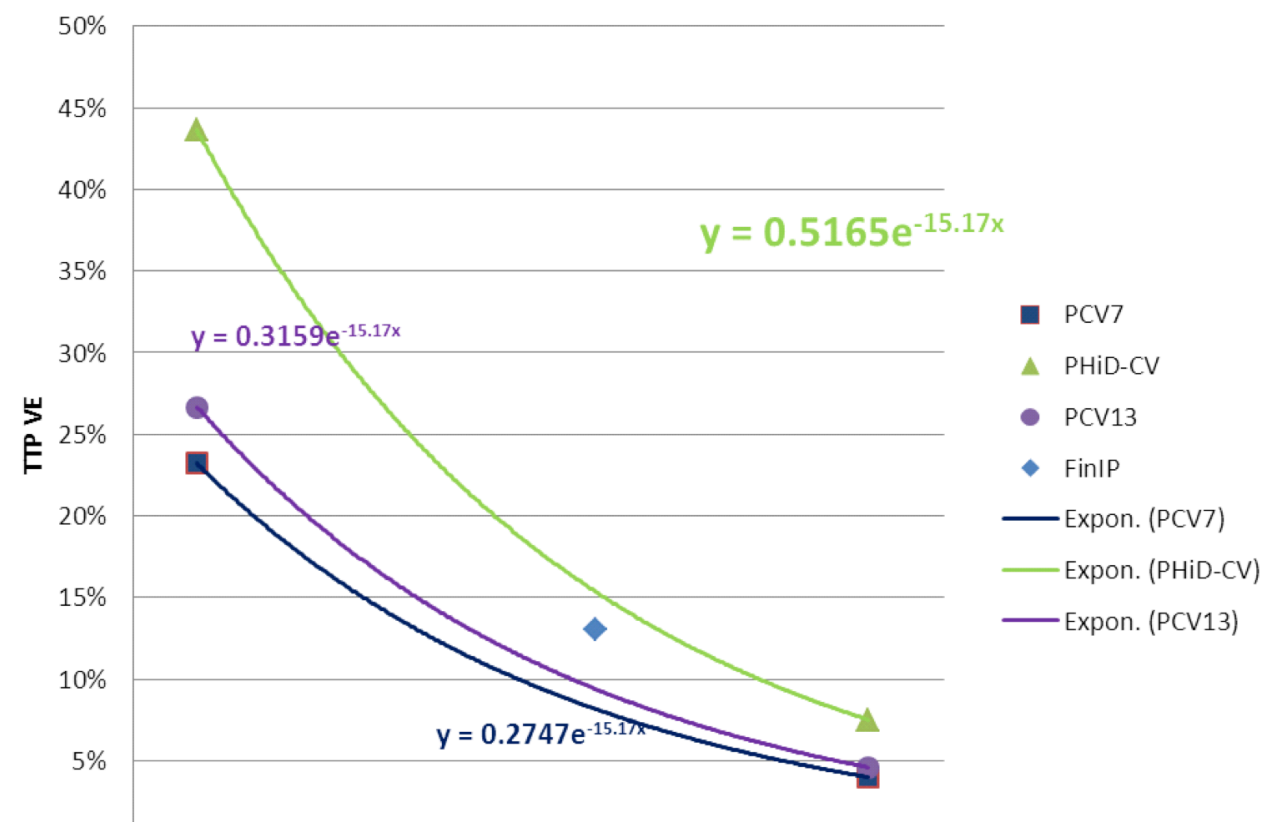


La efectividad final de la vacunación para reducir el número de miringotomías para este estudio se estimó en $30 \%$ para PCV-13 y $49 \%$ para PHiD-CV.

Eficacia de PHiD-CV y PCV-13 contra neumococo en enfermedad invasiva (EI).

La efectividad de ambas vacunas para prevenir las enfermedades invasivas (meningitis y bacteremia) se basó, según consenso de expertos, en la eficacia promedio para los serotipo de neumococo cubiertos por vacuna $(94,7 \%)$, según el estudio de Whitney y colaboradores con la vacuna PCV- ${ }^{23}$. En el caso de la vacuna PHiD-CV se asumió esta eficacia para los serotipos cubiertos $(1,4,5,6 \mathrm{~B}, 7 \mathrm{f}, 9 \mathrm{~V}, 14,18 \mathrm{C}, 19 \mathrm{~F}$ y $23 F)$, y además protección cruzada contra los serotipos $6 A^{23,43-45}$ y $19 A^{23,43,45-49}$, según la información recogida de diversos ensayos clínicos y estudios de fase IV en distintos países. De la misma forma, se estimó la eficacia vacunal de los serotipos presentes en PCV-13. Dada la existencia de abundante evidencia sobre las dificultades que existen para generar una respuesta inmune adecuada contra el $S$. pneumoniae serotipo 3, y la reciente publicación de las minutas del Comité de Inmunizaciones de Gran Bretaña donde se describe la ausencia de efectividad contra este serotipo, luego del análisis de los datos epidemiológicos sobre tipos de neumococo en enfermedad invasiva en Inglaterra y Gales hasta la semana 14 del $2012^{50}$, se asumió una eficacia de 0 para este serotipo. Las Tabla 8 presenta una descripción general de las eficacias utilizadas para PHiD-CV y PCV-13.

Teniendo en cuenta la prevalencia de los distintos serotipos de neumococo en meningitis y bacteremia en Chile, así como la eficacia vacunal contra éstos, fue posible estimar una protección directa máxima contra enfermedad invasiva de $80 \%$ para PCV-13 y $76 \%$ para PHiD-CV. El modelo asume la misma eficacia para meningitis y para bacteremia.

Finalmente, en escenarios seleccionados se asumió eficacia vacunal de PHiD-CV contra enfermedad invasiva por HiNT, la que fue estimada en base a la descrita para OMA por $\mathrm{HiNT}^{36}$. Se estimó una eficacia del 35\%, aunque es posible alcanzar eficacias vacunales superiores para enfermedad invasiva por HiNT. De esta forma, en los análisis de sensibilidad se evaluó eficacias superiores. 
Tabla 8. Resumen de las Eficacias Vacunales (EV) utilizadas para PCV-13 y PHiD-CV

\begin{tabular}{|c|c|c|c|c|}
\hline Eficacia Vacunal & Agente & PHiD-CV & PCV13 & Referencias \\
\hline \multirow{2}{*}{$\begin{array}{l}\text { Enfermedad Invasiva } \\
\text { (serotipo/agente } \\
\text { específica) }\end{array}$} & $\begin{array}{l}\text { Tipos de St. } \\
\text { pneumoniae } \\
\text { adicionales }\end{array}$ & $\begin{array}{c}\text { Igual al promedio } \\
\text { de la EV de los } \\
\text { tipos en PCV7 } \\
(94,7 \%)\end{array}$ & $\begin{array}{l}\text { Igual al promedio de la } \\
\text { EV de los tipos en } \\
\text { PCV7 }(94.7 \%)\end{array}$ & \multirow[t]{2}{*}{23} \\
\hline & $\begin{array}{l}\text { St. Pneumoniae } \\
\text { tipo } 3\end{array}$ & -- & $0 \%$ & \\
\hline \multirow{2}{*}{$\begin{array}{l}\text { Neumonía } \\
\text { (sin especificar } x \text { agente) }\end{array}$} & $\begin{array}{l}\text { Hospitalizada } \\
\text { (Conf. Rx) }\end{array}$ & $23,4 \%$ & $23,4 \% \%$ & \multirow{2}{*}{$24-33$} \\
\hline & $\begin{array}{l}\text { Ambulatoria } \\
\text { (Clinica) }\end{array}$ & $7,3 \%$ & $7,3 \%$ & \\
\hline \multirow{3}{*}{$\begin{array}{l}\text { Otitis Media Aguda } \\
\text { (por tipo de agente) }\end{array}$} & $\begin{array}{l}\text { Tipos de St. } \\
\text { pneumoniae en } \\
\text { PCV7 }\end{array}$ & $69,8 \%$ & $69,8 \%$ & 34 \\
\hline & $\begin{array}{l}\text { Tipos de St. } \\
\text { pneumoniae } \\
\text { adicionales }\end{array}$ & $-33 \%$ & $-33 \%$ & \multirow[t]{2}{*}{35} \\
\hline & HiNT & $20,5 \%$ & $-11 \%$ & \\
\hline \multirow{2}{*}{$\begin{array}{l}\text { Protección Cruzada (solo } \\
\text { en enfermedad invasiva) }\end{array}$} & $6 \mathrm{~A}$ & $76 \%$ & Presente $(94,7 \%)$ & $23,43-45$ \\
\hline & $19 A$ & $50 \%$ & Presente $(94,7 \%)$ & $23,43,45-49$ \\
\hline
\end{tabular}

\section{Efecto Indirecto de vacunas}

El modelo permite incorporar y analizar los efectos indirectos de la vacunación anti-neumocóccica. Básicamente existen dos fenómenos a considerar: el efecto de inmunidad de rebaño (que implica una disminución en el riesgo basal de infección debido a que la cantidad total de enfermos y portadores sanos disminuye al existir una parte de la población que es inmune), y el fenómeno de reemplazo (en donde aumenta el riego basal de infección por los serotipos no cubiertos dado que éstos pueden ocupar parte del nicho ecológico dejado por los serotipos cuya prevalencia disminuye luego de la vacunación). Los efectos indirectos de "inmunidad de rebaño" y "reemplazo de tipos" que generan las vacunas de neumococo, tienen sentidos opuestos y el efecto neto final puede resultar en una disminución efectiva de la frecuencia de infección en los individuos no vacunados. Estos efectos han sido descritos abundantemente para PCV-7 pero su resultado neto final no demuestra una tendencia homogénea en los países estudiados. El resultado final del efecto indirecto neto observado en los EEUU ${ }^{51}$ o Canada ${ }^{52}$ no ha sido replicado en otros países con alta cobertura de PCV-7 (España ${ }^{53}$, Australia ${ }^{54}$ ). Las variables que influyen en estos aspectos son complejas (cobertura de vacunación, matriz de contactos, factores demográficos, fuerza de infección), lo que dificulta el análisis de los resultados actuales. No existe evidencia robusta que permita comparar los efectos indirectos potenciales de ambas vacunas

conjugadas de neumococo. El modelo de cohorte utilizado permite evaluar la "inmunidad de rebaño" y "el reemplazo de tipos" mediante la incorporación de una tasa fija de reducción de la frecuencia de 
enfermedad como resultado del efecto neto final de estos 2 procesos. Dado que no existe una clara tendencia en este sentido, los efectos vacunales indirectos no han sido tenidos en cuenta en el "Caso Base" y solo fueron evaluados en escenarios alternativos. En ellos se utilizó una reducción fija (30\%) de la incidencia de enfermedad invasiva, según el escenario descripto por el CDC de Atlanta para los Estados Unidos ${ }^{55,56}$.

\section{Utilización de Recursos y costos}

El estudio incorporó costos médicos directos en el caso base analizado y costos asociados a la pérdida de productividad o costos indirectos en escenarios alternativos de análisis. En los primeros se consideran aquellos costos atribuibles directamente a la vacunación o a las condiciones médicas analizadas en el caso base (uso de antibióticos, días de internación, estudios por imágenes, laboratorio, etc.), y estos costos fueron los considerados para el cálculo de la Razón de Costo-Efectividad Incremental (RCEI). Dentro de los segundos se consideran los costos por muerte prematura asociados a neumonía y a las enfermedades neumocóccicas invasivas analizadas; y los costos asociados al ausentismo laboral, sea el individuo paciente o cuidador. Todos los costos fueron medidos en Pesos Chilenos corrientes del año 2008 y luego actualizados al 30 de Septiembre del 2012 (variación del 7.6\%) según la calculadora del Índice de Precios al Consumidor del Instituto Nacional de Estadísticas de Chile ${ }^{57}$. La Tabla 9 presenta los costos finales utilizados en el modelo para cada evento estudiado. Los costos incurridos en el tratamiento de condiciones agudas, así como los costos asociados al manejo de secuelas crónicas o la pérdida de productividad asociada a estos eventos fueron llevados a su valor presente neto con una tasa de descuento anual. De la misma forma, las estimaciones sobre Años de Vida Ajustados por Calidad (AVACS) o Años de Vida ganados por el programa de vacunación, también fueron llevadas a su valor presente neto con una tasa de descuento anual. Todos los costos y efectos sanitarios (AVACs y AV) incurridos durante el seguimiento de la cohorte estudiada a lo largo de un horizonte temporal de "toda la vida" fueron descontados utilizando una tasa anual del 6\%, siguiendo las recomendaciones Chilenas ${ }^{58}$.

El método empleado para estimar los costos médicos fue el micro-costeo. En la técnica de micro-costeo se especifican detalladamente los recursos utilizados o consumidos durante el evento estudiado (caso basal), conjuntamente con su tasa de utilización y el precio por unidad. Los costos unitarios para cada recurso consumido en las distintas condiciones analizadas provienen de CIGES $2008^{59}$. En el caso del tratamiento antibiótico ambulatorio se fijó un valor promedio costeando los tratamientos usualmente prescriptos para las condiciones analizadas (según opinión de expertos) tomando los costos de las bases de datos de transacciones de CENABAST y CHILECOMPRAS, año 2008. Para el caso de los niños se tomó en cuenta la diferencia de costos asociada a la dosificación por peso estimándose la misma a partir de las tablas de crecimiento publicadas por la $\mathrm{OMS}^{60}$. En el caso de la secuela auditiva, la tasa de utilización de recursos en general fue obtenida mediante la metodología Delphi (como se mencionó previamente). La única excepción es la tasa de implantes cocleares, donde se asumió que en Chile se llevan a cabo un total de 11 por año ${ }^{61,62}$. Los costos unitarios de los audífonos e implantes fueron ajustados a diciembre del 2008 a partir de las Garantías Explícitas en Salud ${ }^{63}$. Para el caso de las baterías utilizadas tanto para los audífonos como para el implante y el procesador de éste sus costos se estimaron como un 
porcentaje sobre el valor del audífono o implante respectivamente. Para los pacientes que recibieron un implante coclear se asumió que el mismo implica un recambio de batería cada 3 años y un recambio de procesador cada 15 años. En cuanto al audífono, se asumió que este se recambia en promedio cada 10 años. La Tabla 9 muestra los costos finales por cada condición, en forma separada para pacientes pediátricos y adultos. Finalmente, las cantidades y las tasas de uso fueron estimadas utilizando la metodología Delphi. De esta forma se obtuvieron por ejemplo, el número de consultas por casos, días de internación, número de radiografías, etc.

Tabla 9. Lista de costos incluidos en el modelo

\begin{tabular}{|c|c|c|}
\hline \multirow{2}{*}{ Costos de cada evento } & \multicolumn{2}{|c|}{ Costos Estimados } \\
\hline & $\begin{array}{c}\text { Niños } \\
\text { (<16 años) }\end{array}$ & Adultos \\
\hline \multicolumn{3}{|l|}{ Costo promedio por episodio agudo } \\
\hline Neumonía (pacientes hospitalizados) & $\$ 378.205,02$ & $\$ 486.820,17$ \\
\hline Neumonía (pacientes ambulatorios) & $\$ 34.989,85$ & $\$ 40.315,96$ \\
\hline Miringotomía & $\$ 17.833,41$ & $\$ 28.205,94$ \\
\hline Otitis Media Aguda (ambulatoria) & $\$ 19.844,92$ & $\$ 18.565,55$ \\
\hline Meningitis (paciente hospitalizado) & $\$ 1.300 .472,27$ & $\$ 1.370 .570,92$ \\
\hline Bacteriemia (paciente hospitalizado) & $\$ 325.531,10$ & $\$ 946.675,78$ \\
\hline \multicolumn{3}{|l|}{ Costo promedio por secuelas } \\
\hline Secuela neurológica por meningitis (excepto hipoacusia) & $\$ 122.404,29$ & $\$ 33.207,60$ \\
\hline Hipoacusia & $\$ 78.927,34$ & $\$ 102.614,77$ \\
\hline Secuela de $\mathrm{OMA}^{2}$ & $\$ 78.927,34$ & $\$ 102.614,77$ \\
\hline
\end{tabular}

El costo de la campaña de vacunación es calculado por el modelo teniendo en cuenta el número promedio de dosis administradas, el porcentaje de la población que recibe la vacuna (cobertura de la vacunación) y otros gastos de implementación como insumos, recursos humanos, etc. El costo total por persona vacunada con esquema completo fue estimado en $\$ 19.909$ (para PHiD-CV) y 23.039 (para PCV13), valor que incluye las tres dosis de la vacuna, y al que hay que agregarle un $5 \%$ de pérdida por desperdicio y 1 dólar por gastos de administración ${ }^{64}$ en cada aplicación (equivalente a un dólar estadounidense a tasa de cambio comercial ${ }^{65}$. El precio por dosis tomado del Fondo Rotatorio de OPS (licitación del 2012) fue 14,12 dólares para PHiD-CV y 16,34 dólares para PCV-13 ${ }^{66}$, con una tasa de cambio de 470 pesos chilenos por dólar. En el caso base se asumió que el 95\% de la población a vacunar recibió el esquema completo.

En escenarios adicionales del análisis se consideraron los costos asociados a pérdida de productividad incurridos por tres motivos: la mortalidad prematura de los individuos que fallecen por las enfermedades consideradas, el ausentismo laboral del enfermo adulto y el costo del cuidador de un 
paciente pediátrico. Para calcular los costos indirectos asociados con mortalidad prematura se estimó el valor presente neto de las ganancias esperadas de por vida para una persona muriendo a una determinada edad (con un descuento de $6 \%$ anual). En cuanto a la pérdida laboral por ausentismo, el modelo calcula el valor del tiempo perdido fuera del trabajo para pacientes empleados en edad de trabajar (16-74) o padres de pacientes de hasta 15 años, asumiendo que el tiempo perdido por padres o por pacientes es el mismo. Para los cálculos se consideró un sueldo anual promedio de entre $\$$ 2.371 .859 y $\$ 4.163 .793^{67}$, dependiendo de la edad de la persona, con un porcentaje la población efectivamente ocupada de entre $17,1 \%$ y $75,8 \%{ }^{68}$.

Utilidades

El modelo utiliza dos tipos de valores de utilidad: aquellos valores de utilidad normativa (cuál es la utilidad promedio de vivir un año para la población general) y las disutilidades asociadas a las enfermedades (cuánto disminuye la utilidad normativa en un paciente que presenta determinada condición). Debido a la falta de datos locales todos los valores de utilidades fueron obtenidos de fuentes internacionales. La Tabla 10 muestra la utilidad normativa asignada a cada edad, mientras que la Tabla 11 muestra las disutilidades (y sus fuentes de referencia) empleadas por el modelo en cada condición, medidas como la cantidad de utilidad perdida en un año. Para la mayoría de los pacientes la reducción en la calidad de vida asociada al episodio agudo se limita a un período corto de tiempo (una a dos semanas para el caso de neumonías, meningitis o bacteriemias y uno o dos días para las OMAs). Es por eso que las disutilidades generadas por estos episodios agudos son pequeñas (rango entre 0,005 y $0,023)$, en términos anuales. En cambio, para los pacientes con secuelas a largo plazo la pérdida anual de utilidad es sustancial (desde 0,090 por la hipoacusia secundaria a OMA, hasta 0,400 en el caso de las secuelas neurológicas no auditivas dejadas por la meningitis). Estos valores son utilizados para calcular los Años de Vida Ajustados por Calidad (AVACs) perdidos en la población general. Para el cálculo, aquellas utilidades perdidas por muerte prematura o morbilidad asociada a los eventos estudiados fueron llevadas a su valor presente neto usando una tasa de descuento anual de 6\%. Para ello se consideró la expectativa de vida previamente mencionada ${ }^{9}$, empleando las utilidades normativas para cada edad.

Tabla 10. Utilidades para la población general

\begin{tabular}{cc}
\hline Grupos de edad & Utilidad \\
\hline$<16$ años & 0,91 \\
$16-24$ años & 0,91 \\
$25-34$ años & 0,91 \\
$35-44$ años & 0,88 \\
$45-54$ años & 0,85 \\
$55-64$ años & 0,79 \\
$65-74$ años & 0,78 \\
$\geq 75$ años & 0,73 \\
\hline Los valores están basados en las utilidades normativas para hombres y mujeres obtenidas de la Encuesta de Salud de Inglaterra $(1996)^{69}$.
\end{tabular}


Tabla 11. Disutilidades anualizadas según condición

\begin{tabular}{|c|c|c|}
\hline & Disutilidad & Fuente \\
\hline \multicolumn{3}{|c|}{ Disutilidades a corto plazo asociadas con patologías agudas ${ }^{1}$} \\
\hline Neumonía (internación) & 0,008 & $\begin{array}{c}\text { Asumido igual al de los pacientes internados } \\
\text { por bacteremia. }\end{array}$ \\
\hline Neumonía (ambulatoria) & 0,006 & Bennett (2000). ${ }^{70}$ \\
\hline Otitis Media Aguda (ambulatoria) & 0,005 & $\begin{array}{l}\text { Oh (1996), citado por Melegaro y Edmunds } \\
\qquad(2004))^{71,72}\end{array}$ \\
\hline OMA con miringotomía & 0,005 & $\begin{array}{c}\text { Asumido igual a la Otitis Media Aguda sin } \\
\text { miringotomía. }{ }^{72}\end{array}$ \\
\hline Meningitis neumocóccica & 0,023 & Bennett $(2000) .^{70}$ \\
\hline Bacteremia por neumococo & 0,008 & Bennett $(2000) . .^{70}$ \\
\hline \multicolumn{3}{|c|}{ Disutilidades a largo plazo asociadas a secuelas ${ }^{1}$} \\
\hline Hipoacusia por OMA & 0,090 & Oostenbrink (2002). ${ }^{73}$ \\
\hline Secuelas neurológicas por meningitis & 0,400 & Morrow $(2007) .^{74}$ \\
\hline Hipoacusia por meningitis & 0,200 & Morrow (2007) y Cheng (1999). ${ }^{74,75}$ \\
\hline
\end{tabular}

OMA: Otitis Media Aguda. ${ }^{1}$ Se aplican al momento del evento con el descuento anual correspondiente.

Análisis de Costo-Efectividad

Se escogió como referencia el escenario sin vacunación universal, pero también se evaluó las 2 vacunas estudiadas (PHiD-CV y PCV-13) en entre sí. Los resultados sanitarios y económicos obtenidos por las intervenciones estudiadas fueron confrontados con la referencia a fin de establecer el beneficio sanitario y la diferencia de costos atribuibles a cada intervención. De esta forma fue posible construir la RCEI para cada vacuna (PCV-13 y PHiD-CV), la cual puede interpretarse como el costo requerido para "comprar" una unidad de beneficio sanitario adicional (por ejemplo un año de vida, un año de vida en perfecta salud, etc.) por sobre el comparador de referencia. En el caso base, la RCEI del Caso Base fue calculada considerando únicamente los costos directos. Este parámetro (RCEI) fue luego utilizado para definir la costo-efectividad de la intervención. No existe un criterio universalmente aceptado que defina un umbral de costo-efectividad por encima del cual una estrategia sanitaria no deba ser considerada costo-efectiva. Para el presente trabajo se utilizó el criterio propuesto por la Comisión de Salud y Macroeconomía, la cual define como intervenciones "muy costo-efectivas" aquellas que tienen una TCEI por Año de Vida Ajustado por Discapacidad (AVAD) evitado menor al producto bruto interno (PBI) per cápita del país estudiado. Esta comisión sugiere además que las intervenciones que cuestan menos de tres veces el PBI por año de vida ajustado por disabilidad evitado, podrían considerarse como costoefectivas, o lo que es lo mismo, como una adecuada utilización de los recursos presupuestarios ${ }^{76}$. Este marco referencial es avalado además por la Organización Mundial de la Salud ${ }^{77}$. Siguiendo estos criterios y las Guías Chilenas de Farmacoeconomia ${ }^{78}$ en se estimó un umbral de costo-efectividad de $\$ 7.250 .000$ 
Pesos Chilenos del 2012 (15.400 dólares), equivalente a 1 PBI Chileno para el año 2012 publicado por el Fondo Monetario Internacional ${ }^{79}$.

Finalmente se realizó un análisis de sensibilidad univariado y probabilístico sobre distintos parámetros incluidos en el modelo a fin de evaluar su efecto sobre la comparación entre vacunas y la situación actual. Cada uno de estos parámetros fue variado entre un rango de valores, por encima y por debajo del valor utilizado en el caso base, según lo descripto previamente ${ }^{80}$. La RCEI fue calculada nuevamente con cada cambio y comparada con el umbral de costo-efectividad seleccionado. El resultado obtenido fue considerado robusto si los cambios en la RCEI no fueron de suficiente magnitud como para cambiar la interpretación sobre la costo-efectividad de la vacunación anti-neumocóccica.

Análisis de Diferentes Escenarios de Interés

Para evaluar los resultados esperables en el análisis de costo efectividad ante otros escenarios de interés, se calculó las muertes prevenidas, los costos incrementales, los beneficios sanitarios ganados y la RCEI para cada uno de esos escenarios. Entre los escenarios analizados se encuentran: a- Esquema de inmunización $3+1^{22}$. b- Inmunidad de rebaño: Se incluyó una reducción fija de la incidencia de enfermedad invasiva del 30\% (0-5 años) y 30\% (>5 años) debido los efectos opuestos de la "inmunidad de rebaño" y del "reemplazo de serotipos de neumococo"; estos efectos se neutralizan en cierta medida, produciendo un efecto neto final como el observado en los EEU ${ }^{55,56}$. No se consideró que estos efectos tengan influencia sobre las neumonías ${ }^{81}$, ni la OMA. c- Perspectiva social del análisis, incluyendo los costos por pérdida de productividad por mortalidad prematura, y ausentismo laboral por enfermedad o para el cuidado de un paciente pediátrico. En cuanto a la pérdida laboral por ausentismo, el modelo calcula el valor del tiempo perdido fuera del trabajo para pacientes empleados en edad de trabajar (16-74) o padres de pacientes de hasta 15 años, asumiendo que el tiempo perdido por padres o por pacientes es el mismo. d- Descuento de costos y beneficios al 3\%. e- Eficacia contra $\mathrm{H}$. influenzae no tipificable en EI para PHiD-CV. f- Secuelas auditivas incluidas en el análisis. g- PCV-13 con eficacia contra St. Pneumoniae tipo 3. h- PHiD-CV sin protección cruzada contra St. Pneumoniae tipo 6A. i- PHiD-CV sin protección cruzada contra St. Pneumoniae tipo 19A. j- Igual eficacia de PHiD-CV y PCV-13 contra enfermedad invasiva.

Se consideró para el caso base que PCV-13 no tiene eficacia contra St. Pneumoniae tipo 3, dado que el serotipo 3 de neumococo presenta una serie de evidencias en este sentido, que lo hacen único entre los serotipos de neumococo. El estudio de Prymula y col., $2006^{36}$ con la vacuna $11 \mathrm{Pn}$-PD no pudo demostrar protección contra OMA asociada a el St. pneumoniae serotipo 3. Poolman y col., $2009^{82}$ han descrito la tendencia hacia una reducción en la eficacia contra OMA por serotipo 3, particularmente luego de la dosis de refuerzo. El St. pneumoniae serotipo 3 en la vacuna PCV-13, también demostró una respuesta inmunológica débil similar luego de la dosis de refuerzo en los EEUU (fase II) ${ }^{83,84}$, Francia (fase III) ${ }^{85,86}$, Alemania $^{87}$, Polonia $\left(\right.$ fase III) ${ }^{88}$, Italia (fase III) ${ }^{89}$ y España (fase III) ${ }^{90}$. Si bien los estudios de 
inmunogenicidad en España e Italia muestran un ligero aumento en el título de anticuerpos contra el serotipo 3 luego de la dosis de refuerzo, los mismos fueron muy leves y no significativos.

Además, el serotipo 3 de neumococo posee una cápsula polisacárida mucho más desarrollada y densa que otros neumococos, lo que lo hace menos vulnerable a la opsonofagocitosis mediada por anticuerpos $^{82,91}$. Esta característica hace que la enfermedad asociada al serotipo 3 sea difícil de prevenir con anticuerpos anticapsulares. Ya en la era previa a los antibióticos, el efecto terapéutico (evitar la muerte por neumonía) del tratamiento con antisuero contra el serotipo 3 era nulo, a diferencia de lo observado con varios otros tipos de neumococo ${ }^{92}$. La información presentada parece indicar que la respuesta inmune inducida contra el serotipo 3 por las vacunas conjugadas de neumococo, no es suficiente para proteger contra la enfermedad clínica. Poolman y col, $2009^{82}$, han investigado estos hechos y desarrollado las siguientes conclusiones. El St. pneumoniae serotipo 3 genera un impedimento en la capacidad natural de responder contra el polisacárido nativo del serotipo 3 (y por ende contra la infección natural) como consecuencia de la exposición previa al antígeno del serotipo 3 conjugado de las vacunas actuales. El polisacárido capsular que se expresa en abundancia en muchas cepas serotipo 3, puede hacer al St. Pneumoniae serotipo 3 menos susceptible a la defensa mediada por anticuerpos en el oído. La formación de biofilms en el oído medio por parte de la cápsula del St. Pneumoniae serotipo 3, puede ocasionar que los anticuerpos contra los polisacáridos vacunales generados por las vacunas no sean protectivos. Por último, se consideró la reciente publicación de las minutas del Comité de Inmunizaciones de Gran Bretaña donde se describe la ausencia de efectividad contra este serotipo, luego del análisis de los datos epidemiológicos sobre tipos de neumococo en enfermedad invasiva en Inglaterra y Gales hasta la semana 14 del $2012^{50}$.Por estos motivos, el caso base se modelo sin eficacia en PCV-13 contra el St. Pneumoniae tipo 3, y si se la incorporó en escenarios adicionales.

\section{Calibración del modelo a la realidad Chilena}

El modelo permite simular los resultados esperables de los eventos estudiados para el escenario sin vacunación (ver Tabla 12). Estos resultados pueden ser contrastados con la realidad observada en Chile. Los resultados estimados fueron comparados con información recientemente publicada observándose una buena correlación entre los datos ${ }^{3}$. 
Tabla 12. Resultados sanitarios y económicos sin vacunación

\begin{tabular}{|c|c|}
\hline Resultados Sanitarios (casos) $^{\top}$ & \\
\hline Total Neumonías & 242.857 \\
\hline Neumonías Hospitalizadas & 36.872 \\
\hline Neumonías Ambulatorias & 205.985 \\
\hline Vistas Medicas por OMAs & 186.720 \\
\hline Miringotomías & 5.242 \\
\hline Total Meningitis por Neumococo & 192 \\
\hline Secuelas de Meningitis por Neumococo & 52 \\
\hline Total Bacteremia por Neumococo & 193 \\
\hline Resultados Sanitarios (muertes) ${ }^{1}$ & \\
\hline Neumonías & 98 \\
\hline Meningitis por Neumococo & 21 \\
\hline Bacteremia por Neumococo & 12 \\
\hline Total Muertes & 131 \\
\hline AVACs perdidos ${ }^{2}$ & \\
\hline Neumonías & 3.286 \\
\hline Meningitis por Neumococo & 2.686 \\
\hline Bacteremia por Neumococo & 15 \\
\hline OMA & 1.415 \\
\hline Total AVACs perdidos (Morbilidad) & 7.402 \\
\hline Total Años de Vida de la Cohorte & 16.847 .159 \\
\hline Costos Directos $^{2,3}$ & \\
\hline Neumonías & $\$ 84.678 .590 .627$ \\
\hline Meningitis (todas) & $\$ 769.079 .502$ \\
\hline Secuela de Meningitis & $\$ 473.129 .079$ \\
\hline Bacteremia (todas) & $\$ 1.635 .403 .678$ \\
\hline OMA (VM + Miringotomías) & $\$ 5.553 .531 .619$ \\
\hline Secuela de OMA & $\$ 0$ \\
\hline Total Costos Directos & $\$ 93.109 .734 .504$ \\
\hline Total Costos Directos (Descontados 6\%) & $\$ 24.387 .708 .414$ \\
\hline
\end{tabular}

AVACS: Años de Vida Ajustados por Calidad; OMA: Otitis Media Aguda.

${ }^{1}$ Los datos reportados corresponden al número absoluto de casos observados al seguir una cohorte del Chile hasta los 10 años de vida.

${ }^{2}$ Los AVACs perdidos y los costos reportados corresponden al seguimiento de una cohorte del Chile por toda la vida.

${ }^{3}$ Los costos son medidos en Pesos Chilenos del año 2012, Tasa de cambio a Dólar (EEUU); 1 dólar $=470$ pesos chilenos.

${ }^{1,2}$ Los beneficios sanitarios y económicos son reportados sin descuento.. 


\section{Referencias}

1. Standaert B, Demarteau N, Tailbird S, Mauskopf J. Modelling the effect of conjugate vaccines in pneumococcal disease: Cohort or population models? Vaccine 28S (2010) G30-G38.

2. Knerer G, Ismaila A, and Pearce D. Health and economic impact of PHiD-CV in Canada and the UK: a Markov modelling exercise. Journal of Medical Economics Vol. 15, No. 1, 2012, 1-16.

3. García Martí S, Colantonio L, Bardach A, Lopez A, Caporale J, Augustovski F, Pichon Riviere A, Knerer G, Gomez JA. A Cost-Effectiveness Analysis of a 10-Valent Pneumococcal Conjugate Vaccine in Children in Six Latin American Countries. Value in Health 2011 14: A538.

4. Bardach A, Ciapponi A, Garcia-Marti S, Glujovsky D, et al. Epidemiology of acute otitis media in children of Latin America and the Caribbean: a systematic review and meta-analysis. Int J Pediatr Otorhinolaryngol. 2011 Sep;75(9):1062-70. Epub 2011 Jun 12.

5. Gentile A, Bardach A, Ciapponi A, Garcia-Marti S, Aruj P, et al. Epidemiology of community-acquired pneumonia in children of Latin America and the Caribbean: a systematic review and meta-analysis. Int J Infect Dis. 2012 Jan;16(1):e5-e15. Epub 2011 Nov 6.

6. Linstone HA, Turoff M. The Delphi Method. Techniques and Applications. Los Ángeles: University of Southern California, 2002.

7. Bernstein SJ, Hofer TP, Meijler AP, Rigter H. Setting standards for effectiveness: a comparison of expert panels and decision analysis. Int J Qual Health Care 1997; 9(4): 255-63.

8. Instituto Nacional de Estadísticas de Chile y Comisión Económica para América Latina y el Caribe, División de Población, Centro Latinoamericano y Caribeño de Demografía. Proyecciones y Estimaciones de Población. Total País. Período de Información: 1950-2050. http://www.ine.cl/canales/chile_estadistico/demografia_y_vitales/proyecciones/Informes/Microsof t\%20Word\%20-\%20InforP_T.pdf; accedido en Noviembre del 2012.

9. López AD, Salomon J, Ahmad O, Murray CJL, Mafat D. Life Tables for 191 Countries: Data, Methods and Results: World Health Organization. 2012. http://apps. who.int/ghodata/?vid=60330; accedido en febrero del 2012.

10. División de Planificación Sanitaria. Departamento de Estadísticas e Información de Salud. Ministerio de Salud de Chile. Comunicación personal. Abril, 2009. http://www.deis.cl/tema-2-conozcanos/

11. World Health Statistics. World Health Organization, 2007. [Citado: 04.05.2009]; Disponible en: www.who.int/whosis

12. López B I, Sepúlveda B H, Valdés I I. Frecuencia de otitis media aguda en menores de 5 años bajo control. Pediatría (Santiago de Chile) 1998; 41(1/2): 21-5.

13. Rosenblüt A, Napolitano C, Pereira A, Kolhe D, Moreno C, Lepetic A, Colindres R, Ortega-Barria E. Streptococcus pneumoniae and non-typeable Haemophilus influenza: Bacterial pathogens causing acute otitis media in Chilean children aged $<5$ years. ISPPD: 8th International Symposium on Pneumococci and Pneumococcal diseases, Brazil. (11-15 March 2012). Poster103. (http://www2.kenes.com/ISPPD/Scientific/Documents/FinalAbstractbook.pdf; accedido en Noviembre 2012.

14. Cintra O, Iwamoto M, Iwamoto M, Delcaro L, Domingos J, Paula F, Ferraz I, Matsuno A, Arruda $\mathrm{E}$ : Incidence of acute otitis media (AOM) and community acquired pneumonia (CAP) in a Brazilian community level primary care services (PCS) [abstract]. Pediatr Infect Dis J 2009, 28(6):P165.

15. Informe Regional de SIREVA II: datos por país y por grupos de edad sobre las características de los aislamientos de Streptococcus pneumoniae, Haemophilus influenzae y Neisseria meningitidis en procesos invasores, 2000-2005. Washington, D.C: Organización Panamericana de la Salud; 2007. 
16. Informe Regional de SIREVA II, 2006: datos por país y por grupos de edad sobre las características de los aislamientos de Streptococcus pneumoniae, Haemophilus influenzae y Neisseria meningitidis en procesos invasores. Washington, D.C: Organización Panamericana de la Salud; 2008.

17. Informe Regional de SIREVA II, 2007: datos por país y por grupos de edad sobre las características de los aislamientos de Streptococcus pneumoniae, Haemophilus influenzae y Neisseria meningitidis en procesos invasores. Washington, D.C: Organización Panamericana de la Salud; 2008.

18. Informe Regional de SIREVA II, 2008: datos por país y por grupos de edad sobre las características de los aislamientos de Streptococcus pneumoniae, Haemophilus influenzae y Neisseria meningitidis en procesos invasores. Washington, D.C: Organización Panamericana de la Salud; 2009.

19. Informe Regional de SIREVA II, 2009: datos por país y por grupos de edad sobre las características de los aislamientos de Streptococcus pneumoniae, Haemophilus influenzae y Neisseria meningitidis en procesos invasores. Washington, D.C: Organización Panamericana de la Salud; 2010.

20. Informe Regional de SIREVA II, 2010: datos por país y por grupos de edad sobre las características de los aislamientos de Streptococcus pneumoniae, Haemophilus influenzae y Neisseria meningitidis en procesos invasores. Washington, D.C: Organización Panamericana de la Salud; 2011.

21. Gabastou JM, Agudelo $\mathrm{Cl}$, Brandileone MCC, Castañeda E, et al. Caracterización de aislamientos invasivos de S. pneumoniae, H. influenzae y N. meningitidis en América Latina y el Caribe: SIREVA II, 2000-2005. Rev Panam Salud Publica 2008; 24(1): 1-15.

22. De Wals P, Black S, Borrow R, Pearce D. Modeling the Impact of a New Vaccine on Pneumococcal and Nontypable Haemophilus influenzae Diseases: A New Simulation Model. Clinical Therapeutics/Volume 31, Number 10, 2009.

23. Whitney CG, Pilishvili T, Farley MM, Schaffner W, et al. Effectiveness of seven-valent pneumococcal conjugate vaccine against invasive pneumococcal disease: a matched case-control study. Lancet 2006; 368(9546): 1495-502.

24. Black SB, Shinefield HR, Ling S, Hansen J, et al. Effectiveness of heptavalent pneumococcal conjugate vaccine in children younger than five years of age for prevention of pneumonia Pediatr Infect Dis J 2002; 21(9): 810-5.

25. Hansen J, Black S, Shinefield H, Cherian $T$ y col. Effectiveness of Heptavalent Pneumococcal Conjugate Vaccine in Children Younger Than 5 Years of Age for Prevention of Pneumonia. The Pediatr Infect Dis J. 2006; 25: 779-781.

26. Klugman K, Madhi S, Huebner R, Kohberger R, Mbelle N, Pierce N for the Vaccine Trialists Group. A Trial of a 9-Valent Pneumococcal Conjugate Vaccine in Children with and Those without HIV Infection. New England Journal of Medicine 2003; 349 (14):1341-8.

27. Cutts FT, Zaman SMA, Enwere G, Jaffar S, Levine OS, Okoko JB, et al. Efficacy of nine-valent pneumococcal conjugate vaccine against pneumonia and invasive pneumococcal disease in The Gambia: randomised, double-blind, placebo-controlled trial. Lancet 2005;365(9465):1139-46.

28. Madhi SA, Kuwanda L, Cutland C, Klugman KP. The impact of a 9-valent pneumococcal conjugate vaccine on the public health burden of pneumonia in HIV-infected and -uninfected children. Clinical Infectious Diseases 2005;40(10):1511-8.

29. Lucero MG, Nohynek H, Williams G, Tallo V, y col. Efficacy of an 11-Valent Pneumococcal Conjugate Vaccine Against Radiologically Confirmed Pneumonia Among Children Less Than 2 Years of Age in the Philippines. Pediatr Infect Dis J. 2009; 28: 455-462.

30. Saez-Llorenz et al. Design/setting of COMPAS: A Latin American Trial evaluating the efficacy of 10valent pneumococcal non-typable Haemophilus influenza protein-D conjugate vaccine (PHiD-CV). 29th Annual Meeting of the European Society for Pediatric Infectious Diseases (ESPID), The Hague, The Netherlands, June 7-11, 2011.

31. Tregnaghi et al., Evidencia de la eficacia de la vacuna decavalente antineumococcica conjugada a la proteína D del Haemophilus influenzae no tipificable (PHiD-CV) frente a la neumonía adquirida en la 
comunidad en América Latina: resultados del estudio COMPAS. XIV Congreso Latinoamericano de Infectología Pediátrica (SLIPE), Punta Cana, Republica Dominicana, 25-28 de Mayo 2011.

32. Tregnaghi et al., Evaluating the efficacy of 10-valent pneumococcal non-typable Haemophilus influenzae protein-D conjugate vaccine (PHiD-CV) against community-adquired pneumonia in Latin America. 29th Annual Meeting of the European Society for Pediatric Infectious Diseases (ESPID), The Hague, The Netherlands, June 7-11, 2011.

33. Lucero MG, Dulalia VE, Nillos LT, Williams G, Parreño RAN, Nohynek H, Riley ID, Makela $H$. Pneumococcal conjugate vaccines for preventing vaccine-type invasive pneumococcal disease and $X$ ray defined pneumonia in children less than two years of age. Cochrane Database of Systematic Reviews 2009, Issue 4. Art. No.: CD004977. DOI: 10.1002/14651858.CD004977.pub2.

34. Sáez-Llorens $X$ et al. Efficacy of 10-valent pneumococcal non-typeable Haemophilus influenzae protein D conjugate vaccine (PHiD-CV) against acute otitis media in children in Panama. Abstract presented at the $9^{\text {th }}$ International Symposium on Antimicrobial Agents and Resistance (ISAAR), Kuala Lumpur, 13-15 March 2013.

35. Eskola J, Kilpi T, Palmu A, Jokinen J, et al. Efficacy of a pneumococcal conjugate vaccine against acute otitis media. N Engl J Med 2001; 344(6): 403-9.

36. Prymula R, Peeters P, Chrobok V, Kriz P, et al. Pneumococcal capsular polysaccharides conjugated to protein $D$ for prevention of acute otitis media caused by both Streptococcus pneumoniae and nontypable Haemophilus influenzae: a randomised double-blind efficacy study. Lancet 2006; 367(9512): 740-8.

37. Palmu AAI, Verho J, Jokinen J, Karma P, Kilpi TM. The Seven-Valent Pneumococcal Conjugate Vaccine Reduces Tympanostomy Tube Placement in Children. Pediatr Infect Dis J 2004;23: 732-738.

38. Sarasoja I, Jokinen J, Lahdenkari M, Kilpi T, Palmu AA. Long-term effect of pneumococcal conjugate vaccines on tympanostomy tube placements. Pediatr Infect Dis J 2013;32:517-20.

39. Fireman B, Black SB, Shinefield HR, Lee J, Lewis E, Ray P. Impact of the pneumococcal conjugate vaccine on otitis media. Pediatr Infect Dis J 2003;22:10-6.

40. Poehling KA, Szilagyi PG, Grijalva CG, Martin SW, et al. Reduction of Frequent Otitis Media and Pressure-Equalizing Tube Insertions in Children After Introduction of Pneumococcal Conjugate Vaccine. Pediatrics 2007;119;707.

41. Jardine A, Menzies RI, Deeks SL, Patel MS et al. The Impact of Pneumococcal Conjugate Vaccine on Rates of Myringotomy With Ventilation Tube Insertion in Australia. Pediatr Infect Dis J 2009; 28:7615.

42. Palmu Effectiveness of the 10-valent pneumococcal conjugate vaccine against tympanostomy tube placements in a cluster randomized trial. $7^{\text {th }}$ Extraordinary International Symposium on Recent Advances in Otitis Media (ISRAOM 2013). Abstract FP41, June 13, 2013, Stockholm - Sweden. http://ki.se/sites/default/files/h9_onh_otitismedia2013.pdf

43. Bermal N, Szenborn L, Chrobot A, Alberto E, Lommel P, Gatchalian S et al.: The 10-valent pneumococcal non-typeable Haemophilus influenzae protein $D$ conjugate vaccine (PHiD-CV) coadministered with DTPW-HBV/Hib and poliovirus vaccines: assessment of immunogenicity. Pediatr Infect Dis J 2009, 28: S89-S96.

44. Park IH, Moore MR, Treanor JJ, Pelton SI, Pilishvili T, Beall B et al.: Differential effects of pneumococcal vaccines against serotypes 6A and 6C. J Infect Dis 2008, 198: 1818-1822.

45. De Wals P, Lefebvre B, Defay F, Deceuninck G, Boulianne N, Bourgault A M. Invasive pneumococcal disease in two birth cohorts vaccinated respectively, with 2+1 PCV-7 or PHiD-CV-10 doses. 29th annual meeting for paediatric infectious disease (ESPID), the Hague, the Netherlands, 7-11 June, 2011.

46. Hausdorff WP, Hoet B., Schuerman L. Do pneumococcal conjugate vaccines provide any crossprotection against serotype 19A? BMC Pediatrics 2010, 10(4): 1-7. 
47. Jokinen et al,. Impact of 10-valent pneumococcal conjugated vaccine (PCV10) on invasive pneumococcal disease (IPD) among vaccine-elegible children in Finland. $8^{\text {th }}$ World Congress of the WSPID, Cape Town, South Africa, 2013.

48. Mrkvan T, Hoet B, Adegbola RA, Van Dyke M, Hausdorff WP. Serotype 19A and the 10-valent pneumococcal nontypeable Haemophilus influenza protein D conjugate vaccine (PHiD-CV): Lessons learned to date. $31^{\text {st }}$ Annual Meeting of the ESPID, Milan, Italy, 2013.

49. Domingues CMAS, Verani JR, Montenegro ER, Brandileone MCC, Flannery B, de Oliveira LH, dos Santos JB, Moraes JC. Effectiveness of ten-valent pneumococcal vaccine against invasive pneumococcal disease in Brazil: A matched case-control study. 9th ISPPD, Hyderabad, India, 2014. Abstract OP-236.

50. Joint Committee on Vaccination and Immunisation (UK). Pneumococcal sub-comittee. Minute of meeting on Wednesday 30 May 2012. https://www.wp.dh.gov.uk/transparency/files/2012/07/JCVIminutes-Pneumococcal-sub-committee-meeting-held-on-30-May-2012.pdf[Accessed: Nov 2012].

51. Hicks LA, Harrison LH, Flannery B, Hadler JL, et al. Incidence of pneumococcal disease due to nonpneumococcal conjugate vaccine (PCV7) serotypes in the United States during the era of widespread PCV7 vaccination, 1998-2004. J Infect Dis 2007; 196(9): 1346-54.

52. Kellner JD et al. Progress in the prevention of pneumococcal infection. CMAJ 2005; 173(10):11491151.

53. Ardanuy $C$ et al. Epidemiology of invasive pneumococcal disease among adult patients in Barcelona before and after pediatric 7-valent pneumococcal conjugate vaccine introduction, 1997-2007. Clin Infect Dis 2009; 48(1):57-64.

54. Hanna JN, Humphreys JL, Murphy DM. Invasive pneumococcal disease in Indigenous people in north Queensland: an update, 2005-2007. Med J Aust 2008; 189(1):43-46.

55. Centers for Disease Control and Prevention. 2005. Direct and indirect effects of routine vaccination of children with 7-valent pneumococcal conjugate vaccine on incidence of invasive pneumococcal disease - United States, 1998-2003. MMWR; 54:893-897.

56. Centers for Disease Control and Prevention. 2008. Invasive pneumococcal disease in children 5 years after conjugate vaccine introduction--eight states, 1998-2005. MMWR Morb Mortal Wkly Rep; 57(6):144-148.

57. Instituto Nacional de Estadísticas de Chile. Calculadora del Índice de Precios al Consumidor. http://encina.ine.cl/calculadoraipc/; accedido en Noviembre del 2012.

58. Ministerio de Salud de Chile. Guía metodológica para la evaluación económica de intervenciones en salud en Chile. 2011. http://desal.minsal.cl/DOCUMENTOS/PDF/2011/Guia_Metodologica_EE_(documento_para_consult a).pdf

59. Centro de Capacitación, Investigación y Gestión para la Salud Basada en Evidencias (CIGES), Universidad de La Frontera, Ministerio de Salud de Chile. Temuco, Chile: 2008. (Datos No Poblicados).

60. Child growth standards. World Health Organization (WHO). [Citado: 18/03/2010]; Disponible en: http://www.who.int/childgrowth/standards/peso_para_edad/en/index.html

61. Berruecos P. Cochlear implants: an international perspective--Latin American countries and Spain. Audiology 2000; 39(4): 221-5.

62. Programa de implantes cocleares del Ministerio de Salud de Chile. Santiago de Chile: Unidad de Discapacidad y Rehabilitación, División Prevención y Control de Enfermedades, Subsecretaría de Salud Pública, Ministerio de Salud de Chile, 2006.

63. Ministerio de Salud. Garantías Explicitas en Salud del Régimen General de Garantías en Salud. Decreto 44, 9 de Enero del 2007. Accedido en Noviembre del 2012. http://www.minsal.gob.cl/portal/url/item/a01c44f31367f1d3e04001011f01714b.pdf 
64. Constenla D. Economic impact of pneumococcal conjugate vaccination in Brazil, Chile, and Uruguay. Rev Panam Salud Publica 2008; 24(2): 101-12.

65. XE Currency Converter. Disponible http://www.xe.com/ict/?basecur=USD\&historical=true\&month=12\&day=28\&year=2010\&sort_by=n ame\&image. $x=42 \&$ image. $y=17$; Accedido el 15 de Setiembre del 2012.

66. OPS. Boletín de Inmunizaciones. Fondo Rotatorio de OPS: precios de vacunas y jeringas 2012. Volumen XXXIV, Número 1 de Febrero 2012, pag. 7.

67. Encuesta Suplementaria de Ingresos, 2010. Instituto Nacional de Estadísticas, Chile. http://www.ine.cl//descarga.aspx?id=3737; accedido en Noviembre 2012.

68. Indicadores de empleo y desempleo. Población total y de 15 años y más por situación en la fuerza de trabajo por Edad, según sexo. Octubre 2012. Instituto Nacional de Estadísticas, Chile.; accedido en Noviembre 2012. http://www.ine.cl/ProductosEstadisticos/Laborales/Producto.aspx?producto=335

69. Health Survey for England. 1996. [Citado: 05/11/2007]; Disponible en: http://www.archive.officialdocuments.co.uk/document/doh/survey96/tab5-29.htm

70. Bennett JE, Sumner W, 2nd, Downs SM, Jaffe DM. Parents' utilities for outcomes of occult bacteremia. Arch Pediatr Adolesc Med 2000; 154(1): 43-8.

71. Oh PI, Maerov P, Pritchard D, Knowles SR, et al. A cost-utility analysis of second-line antibiotics in the treatment of acute otitis media in children. Clin Ther 1996; 18(1): 160-82.

72. Melegaro A, Edmunds WJ. Cost-effectiveness analysis of pneumococcal conjugate vaccination in England and Wales. Vaccine 2004; 22(31-32): 4203-14.

73. Oostenbrink R, Oostenbrink JB, Moons KG, Derksen-Lubsen G, et al. Cost-utility analysis of patient care in children with meningeal signs. Int J Technol Assess Health Care 2002; 18(3): 485-96.

74. Morrow A, De Wals P, Petit G, Guay M, Erickson LJ. The burden of pneumococcal disease in the Canadian population before routine use of the seven-valent pneumococcal conjugate vaccine. Can J Infect Dis Med Microbiol 2007; 18(2): 121-7.

75. Cheng AK, Niparko JK. Cost-utility of the cochlear implant in adults: a meta-analysis. Arch Otolaryngol Head Neck Surg 1999; 125(11): 1214-8.

76. Sachs JD. Macroeconomics and Health: Investing in Health for Economic Development. Report of the Commission on Macroeconomics and Health. Geneva: World Health Organization, 2001.

77. The World Health report 2002: Reducing Risks, Promoting Healthy Life. Geneva: World Health Organization, 2002.

78. Ministerio de Salud de Chile. Guía metodológica para la evaluación económica de intervenciones en salud en Chile. DESAL, 2011. http://desal.minsal.cl/DOCUMENTOS/PDF/2011/Guia_Metodologica_EE_(documento_para_consult a).pdf

79. International Monetary Fund: World Economic and Financial Surveys, World Economic Outlook Database 2012. http://www.imf.org/external/pubs/ft/weo/2012/02/weodata/weorept.aspx?sy=2008\&ey=2012\&scs $\mathrm{m}=1 \& \mathrm{ss} d=1 \&$ sort $=$ country \& $\mathrm{ds}=\% 2 \mathrm{c} \& \mathrm{br}=1 \& \mathrm{c}=228 \& \mathrm{~s}=$ NGDPRPC\%2CNGDPPC\%2CNGDPDPC\%2CPPPP C\%2CPPPEX\%2CPCPI\%2CPCPIPCH\%2CPCPIE\%2CPCPIEPCH\%2CLP\&grp=0\&a=\&pr1.x=64\&pr1.y=17\#CS 7. Accedido en Noviembre 2012.

80. Gomez JA, Tirado JC, Navarro Rojas AA, Castrejon Alba MM, Topachevskyi O. 2013. Costeffectiveness and cost utility analysis of three pneumococcal conjugate vaccines in children of Peru. BMC Public Health. 2013 Oct 30;13:1025.

81. Nelson JC, Jackson M, Yu O, Whitney CG, Bounds L, Bittner R et al. 2008. Impact of the introduction of pneumococcal conjugate vaccine on rates of community acquired pneumonia in children and adults. Vaccine. 2008 Vaccine 26(38):4947-54. 
82. Poolman J et al. 2009. Pneumococcal serotype 3 otitis media, limited effect of polysaccharide conjugate immunisation and strain characteristics. Vaccine 27(24):3213-3222.

83. Bryant KA, Block SL, Scott DA. 2007. Safety and immunogenicity of a 13-valent pneumococcal conjugate vaccine. In: 25th annual meeting of the European Society for Paediatric Infectious Diseases (ESPID), Abstract book. p. 32 [Abstract no. 53].

84. Bryant KA, Block SL, Scott DA. 2008. Safety and immunogenicity of a 4th dose of 13-valent pneumococcal conjugate vaccine in healthy toddlers. In: 26th annual meeting of the European Society for Paediatric Infectious Diseases (ESPID), Abstract book. p. 309 [Abstract no. 600].

85. Grimprel E, Scott D, Laudat F, Baker S, Gruber W. 2008. Safety and Immunogenicity of a 13-valent Pneumococcal Conjugate Vaccine Given with Routine Pediatric Vaccination to Healthy Infants in France, Presented at the 48th annual ICAAC / IDSA 46th Annual Meeting, Washington DC, USA, October 25-28. (http://uploads.renegadedigital.com/Istanbul/grimpel.pdf; accessed on April 17, 2009).

86. Grimprel E., F. Laudat, S.A. Baker, C. Sekaran, W.C. Gruber, D.A. Scott. 2009. Safety and immunogenicity of a 13-valent pneumococcal conjugate vaccine given with routine pediatric vaccination to healthy children in France. Presented at the 27th Annual Meeting of the European Society for Paediatric Infectious Disease (ESPID) Brussels, Belgium, June 9-13.

87. Kieninger DM, Kueper K, Steul K, Juergens C, Ahlers N, Baker S, Giardina P, Gruber W, Scott D. 2008. Safety and Immunologic Non-Inferiority of 13-valent Pneumococcal Conjugate Vaccine Compared to 7-valent Pneumococcal Conjugate vaccine Given as a 4-Dose Series with Routine Vaccines in healthy Infants and Toddlers, Presented at the 48th annual ICAAC / IDSA 46th Annual Meeting, Washington DC, USA, October 25-28.(http://uploads.renegadedigital.com/Istanbul/ kieninger.pdf; accessed on April 17, 2009).

88. Gadzinowski J., E. Daniels, D.A. Scott, S. Patterson, W.C. Gruber, S. Tansey, E. Emini. 2009. Safety and immunogenicity of 13-valent pneumococcal conjugate vaccine with/without polysorbate 80 in healthy infants in Poland. Presented at the 27th Annual Meeting of the European Society for Paediatric Infectious Disease (ESPID) Brussels, Belgium, June 9-13.

89. Esposito S., S. Tansey, A. Thompson, G. Ferrera, A. Maida and G. Bona et al., 2009. Safety and immunologic non-inferiority of 13-valent pneumococcal conjugate vaccine given as a 3-dose series with routine vaccines in healthy children in Italy, Presented at the 27th Annual Meeting of the European Society for Paediatric Infectious Disease (ESPID) Brussels, Belgium, June 9-13.

90. Diez-Domingo J., A. Gurtman, E. Bernaola, F. Gimenez-Sanchez, F. Martinon-Torres and V. PiinedaSolas et al. 2009. Safety and immunogenicity of 13-valent pneumococcal conjugate vaccine in healthy infants and toddlers receiving routine vaccinations in Spain, Presented at the 27th Annual Meeting of the European Society for Paediatric Infectious Disease (ESPID) Brussels, Belgium, June 913.

91. Sven Hammerschmidt, Sonja Wolff, Andreas Hocke, Simone Rosseau, Ellruth Müller, and Manfred Rohde. 2005. Illustration of Pneumococcal Polysaccharide Capsule during Adherence and Invasion of Epithelial Cells. Infect. Immun. 73: 4653-4667.

92. Heffron R. 1939. In: Pneumonia, with special reference to pneumococcus lobar pneumonia. Harvard University Press; p834. 